\title{
AL-IKHTIBĀR AL-MUSTAKHDAMAH LITARQIYATI MAHĀRAH AL KALĀMI FI TA'LĪMI AL-LUGHAH AL-ARABIYYAH
}

\author{
Wahyudi Buska $^{1}$, Nurhasnah ${ }^{2}$ \\ ${ }^{1}$ Universitas Islam Negeri (UIN) Sulthan Thaha Saifuddin Jambi \\ ${ }^{2}$ Institut Agama Islam Negeri (IAIN) Bukittinggi Sumatera Barat \\ wahyudi@uinjambi.ac.id
}

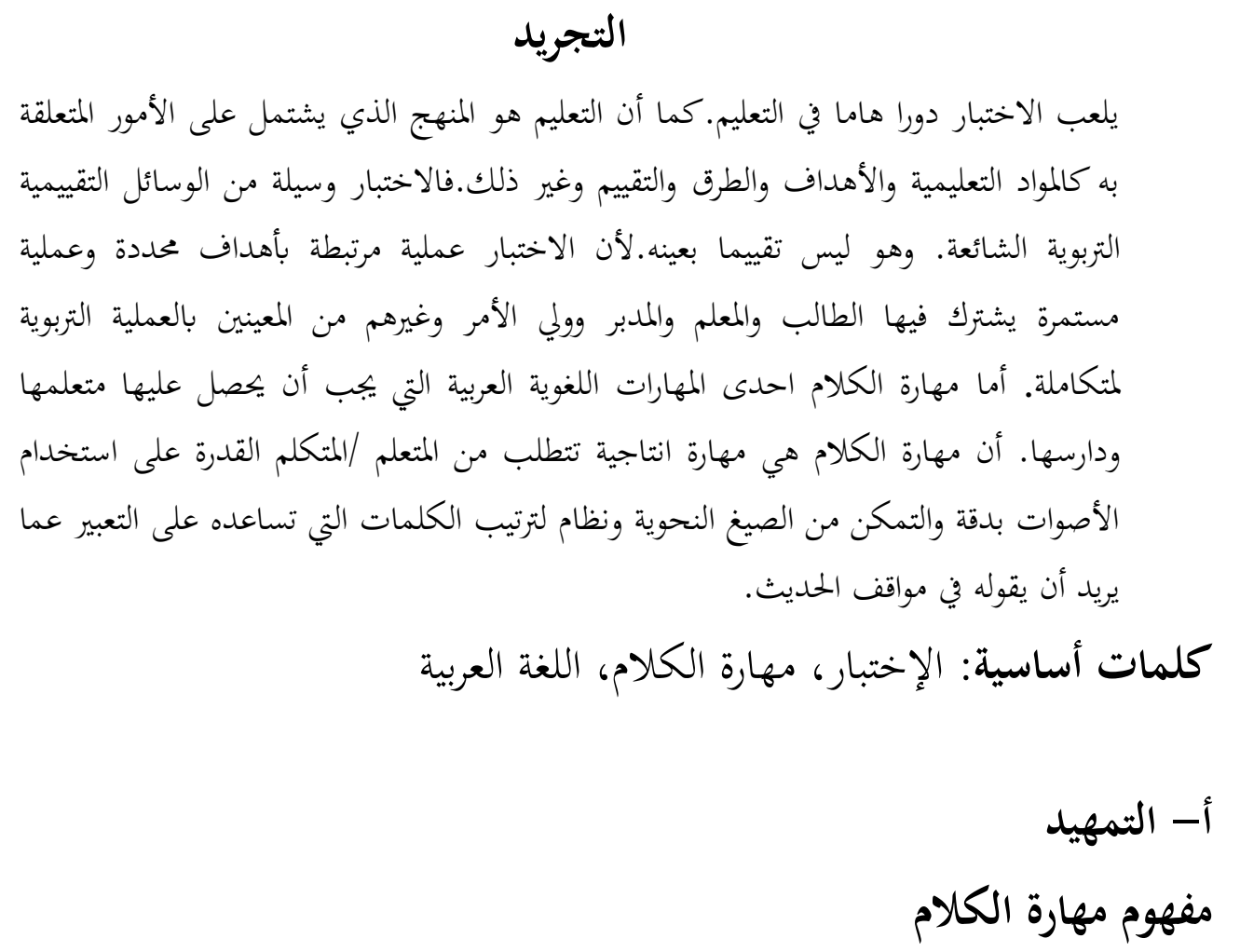

الكالام ليس مجموعة من المهارات اللغوية التنوعة التي يجب أن يتقنها الفرد، حتي يصبح متمكنا محا يريد أن يعبر عنه في يسر، بل أن الكالام له بعض آخر غير هذا البعد اللعوي، و هو البعد المعرين : وهذا المربى يربط بتحصيل المعلومات الحقائق والأفكار والخبرات عن طريق القراءة المتنوعة الواعية، وهذا البعد المعريف يكسب المتكلم عند الكالام الطالاقة اللغوية، و القدرة علي تكوين الجمل، وبناء العبارات الفقرات، وترتيبها وهذا يستدعى التببيه على الإهتمام بالقراءة العامة، والربط بين ما يقرؤه الإنسان، وما يتكلم فيه، ومن أهم ما ندعو ألى قراءته. 
Wahyudi Buska, Nurhasnah: Al-Ikhtibār al-Mustakhdamah Litarqiyati Mahārah al Kalāmi

Fi Ta'līmi al-Lughah al-Arabiyyah

وتتعدد مهارة الكلامم تبعا لعوامل متعددة : جنس المتحدث : فمهارات الذكر في الكلام مختلف مهارات الأنثى، ومنها العمر الزمني: فمهارة الصغار في الكلام تختلف عن مهارات الشباب، ومهارات الشباب تختلف عن مهارات الشيوخ وهكذا، ومنها مستوى التعليمي: فمهارات المستويات التعليمية، وتخصصها تختلف عن بعضها في الكلام، ومنها الخبرات الثقافية، والرصيد اللغوي، وقرب موضوع المتحث عنه، او بعده عن بجال تخصص المتكلم، ودافيعية المتكلم ألى غير ذالك من عوامل وتربل أخرى. - n

$$
\text { ولعل من أبرز من مهارات الكلام ما يلي: }
$$

1. نطق الحروف من مخارجها الأصلية، ووضوحها من المستمع: وتلك مهارات

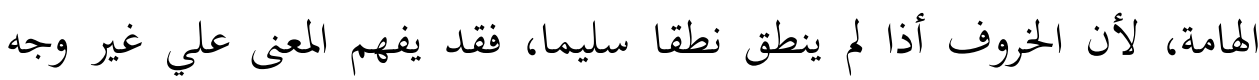

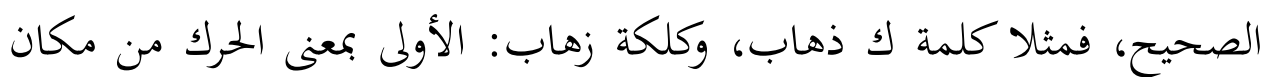

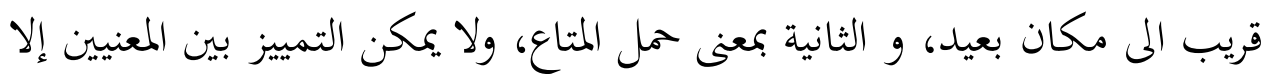
بإخراج اللسان مع حرف الذال في الكلمة الأولى. r.ترتيب الكلام ترتيبا معينا يحقق ما يهدف إليه المتكلم والمستمع على السواء،

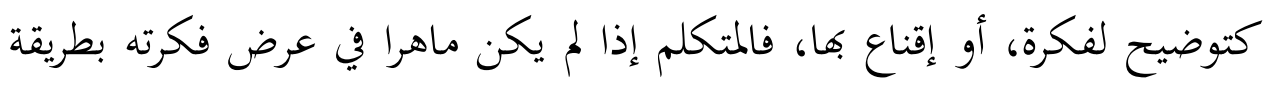
مرتبة تنتقل من البسيط الى المركب، من المجمل إلى المفضل، من المبهم الى لى إلى

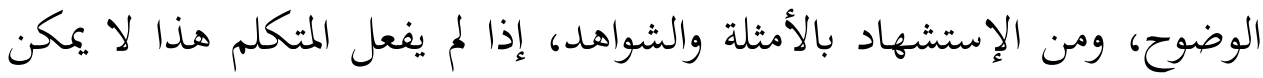
أن يفهم السامعين أو يوصل ما يريد توصيله إليهم.

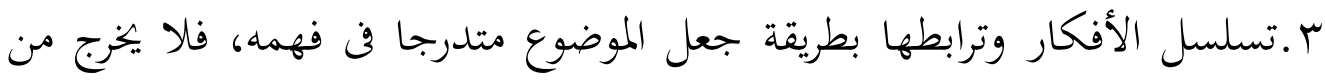
الموضوع الأصلي الى موضوعات فروعيى تبعد السامعين عن الموضوع الأصلي، ولا تكون هناك فواصل في الكلامم تقطعه عن بعض. 
Wahyudi Buska, Nurhasnah: Al-Ikhtibār al-Mustakhdamah Litarqiyati Mahārah al Kalāmi

ع. السيطرة الاتامة على كل ما يقوله خاصة فيما يتعلق بتمام المعني، بكيث لا ينسى مثلا : الخبر إذا بعد المبتدأ، او جواب الشرط بعد بقية إجزاء الجملة الشرطية،

$$
\text { كما لا ينسى ترابط الافكار و تتبعها. }
$$

هـ الضبط نحو الصرفي، تلك مهارة متعلقة بالأداء اللغوى، لأن ضبط بينية مهمة جدا فتغير حركة واحدة من حراكات الكلمة قد يغير معمناها، مثل كلمة: عِبرة عَبرة. فكل كلمة لما معنى، وهذا المعنى مربط بضبتها الصرفي، كما أن الضبط النحوي الأوخر الكلمات له تأثير على المعنى، فمثلا لو قلنا : (شاهد المتفرجين اللاعبون و هم يتنافسون في سباق الفروسية). ولذالك أن الضبط النحوي والصرفي في مهارة ربد منها لتوضيح المعني وصحته، فيراعى التدريب عليها عن طريق تسجيل المتكلم لكامه، ثم إعادة التسجيل، ليعرف الأخطاء التي وقع فيها،

$$
\text { و بحال تصويبها بنفسه، مع مناقسته فيها. }
$$

7. الاقناع وقوة التأثير: وتلك مهارة مهمة تتعلق بغرض الأفكار وتنسيقها، وعرض الأدلة، وادراك مواطن الاتفاق والاختلاف في الموضوع مع الاخرى، ومحاولة التأكيد على مواطن الاتفاق، و تقنيد مواطن الاختلاف، مع ذكر الأداة المقنعة بطريقة مؤثرة، و خيال من التعصب الممقوت، أو الانفعال الزائد، ويتمثل المتكلم في ذالك بقول الله تعالى : ( وجادلهم بالتي هي أحسن، النحل : هب 1 )، فيراعى التدريب على هذه المهارة بمعرفة عناصر الوضوع قبل التكلم فيه، والتخطيط له، وتنسيق الأفكار وتقديم الأعم على المهم، واستعراض كل جواب الموضوع، مع التمهيد المشوق، والعرض الواضح المقنع، والخاتمة المؤثرة. V. استخدام المفردات اللغوية: تعد الألفاظ قوالب للمعانى، واللفظ الواحد قد يؤدى معاني مختلفة مثل: (العين: لحاسة البصر، والعين :لنبع الماء، والعين :للجاسوس، والعين: أسم مدينة)، ومثل: (المغرب: أحد أوقات الصلاة والمغرب: لزم الغروب، والمغرب: اسم الدولة)، ولا يدرك اي معان من هذه المعان الأمن خلال السياق، 
Wahyudi Buska, Nurhasnah: Al-Ikhtibār al-Mustakhdamah Litarqiyati Mahārah al Kalāmi Fi Ta'līmi al-Lughah al-Arabiyyah

فعلى المتكلم أن يحسن أستخدام المفردات اللغوية، ويضع كل لفظ في مكانه

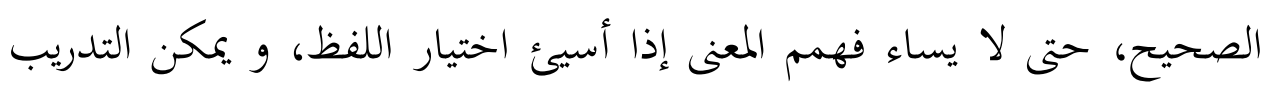
على هذه المهارة : باستخدام الكلمات التى تعطى معاني متعددة في جمل مختلفة إستاء وتوضح كل معنى من معانيها من خلال سياق الجمال.

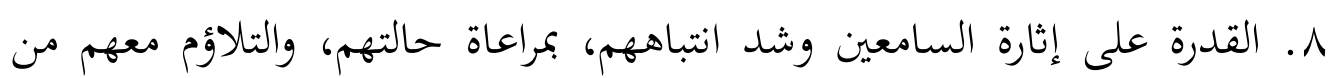

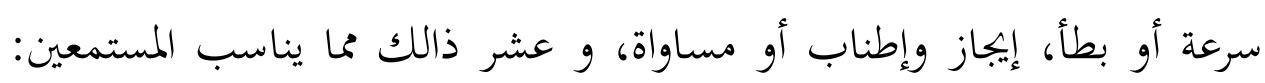
كالسهولة، والصعوبة، والاستطراد.

أجادة فن الالقاء: بما فيه من تنغيم الصوت، وتنويعة، والضبط على ما يراد الضغط وليطراد عليه، وتنبيه السامع على مواقف: التعجب، ولاستفهام، والجمل الاعتراضية، والعائية. فيمثل المتكلم المعنى بالصوت والإشارة.

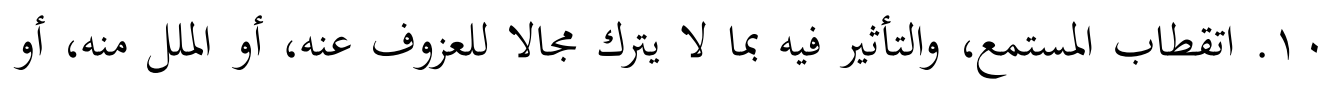
تأتى ذالك باستخدام: حسن العرض، وأسلوب التشويق، وقوة الأداء، والثقة

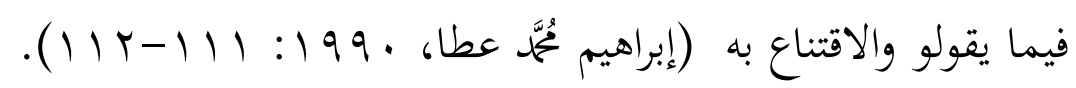
1 ا. القدرة على استخدام الوقفة المناسب، والحركة الجسمية المعبرة، والوسائل

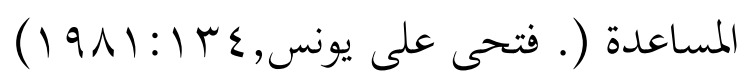

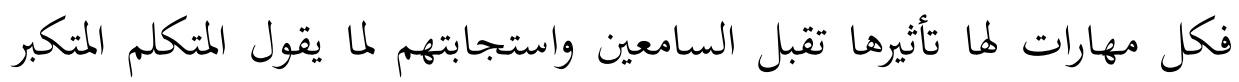
جلسته، لا يستجيب له السامعون، والمتكلم ألى لا يعرف كيف واجه الجماهير

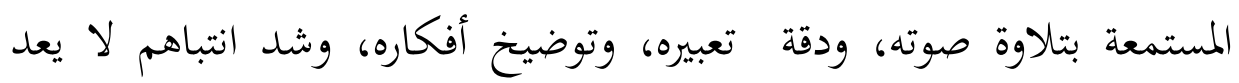

$$
\begin{aligned}
& \text { متمكنا من مهارات الكلام. } \\
& \text { أ. أهداف تدريس الكالام }
\end{aligned}
$$

هناك أهداف كثيرة ومتنوعة للكلام، ويرى وروبرت بولي أن هناك مأين أساسين في أي جهد يقوم به الانسان عند اتصاله بالاخرين عن طريقة اللغة هما: الأفكار

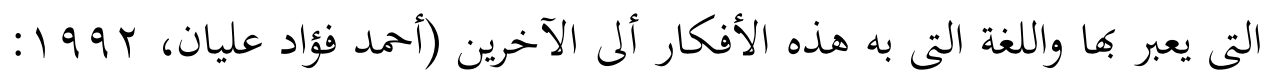


Wahyudi Buska, Nurhasnah: Al-Ikhtibār al-Mustakhdamah Litarqiyati Mahārah al Kalāmi

Fi Ta'līmi al-Lughah al-Arabiyyah

بو). وأهداف اللغة العربية العامة، وهناك خاصة الكلام يمكن توضيحها فيما

أول : أهداف عامة لتعليم مهارة الكلام :

ا ـ أن ينطق المتعلم أصوات اللغة العربية. وأن يؤدى النبر والتنغيم المختلفة وذالك

$$
\text { بطريقة مقبولة من أنباء العربية. }
$$

r. أن ينطق الاصوات التجاورة و المتشابهة.

r. أن يدرك الفرق فن النطق بين الحركات القصيرة والحركات الطويلة.

ـ. أن يعبر عن أفكار مستخدما الصيغ النحوية المناسبة.

ه. أن يعبر عن أفكار مستخدما النظام الصحيح لتركيب الكلمة في العربية حصة

في لغة الكالام

T. . أن يستخدم بعض خصائص اللغة في التعبير الشوي مثل : التذكير والتأنيث

وتمييز العدد والحل ونظام الفعل وأزمنة وغير ذالك مما يلزم المتكلم العربية.

V. أن يكسب ثروة لفظية كالام مناسباة لعمره ومستوى نضجه وقدراته، وأن

$$
\text { يستخدم هذه الثروة في أتمام عمليات اتصالية عصرية. }
$$

1. أن يستخدم بعض أشكال الثقافية العربية المقبولة والمناسبة لعمره ومستواه

الاجتماعية وطبيعة عمله، وأن يكسب بعض المعلومات الأساسية عن الاتراث

$$
\text { العربي والإسالامي (الناقة محمود كامل، } 1910 \text { 101-10V: }
$$

\section{أهمية مهارة الكلام}

لقد كان الكلام أول صورة من صور الأداء اللغوى، وعلى الرغم من تعدد هذه الصور الان فمازل الكالام والوسيلة الأساسية للتوصيل، أذا يرى الباحثون اللغويون في معظمهم من النشاط اللغوى يكون نشاطا شفهيا ويشكل الكالام آدة أتصال سريعة بين الإفراد ، أو بين الفرد و المجتمع، و الإنسان الذي يمسك بزمام الكلام و يكون قادرا علي ضبطه وإرادة غالبا ما يكون ذالك سببا فن أحرازه للنجاح في حياته العامة والخاصة، لإن 
الكلام هو ألى يرسم صورة الشخصية في أذهان الآخرين، ومن لا يستطيع التحكم في

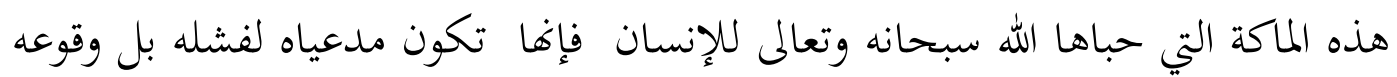
في كثير من المزالق فقد جاء في الأثر أن مصرع الرجل بين فكيه، واللسان هو المقوال (أداة الكلام)، وكثيرا ما تكون لباقة المرء في كلامه طريقا سهلا للوصول ألى أهدافه. والمجتمعات المتحضرة لا تفرق بين الكلام الشفوي والكلام التحريري من حيث الأهمية في التوثيق، لأنه كلما تقدمت الامة لأدائها و ضبطها (الشنوط،يُمَّم صالح، 1990:

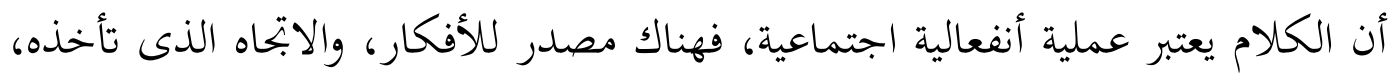
والمواقف الذي تقل فيه، والشخص الذي تقال له. معنى هذا أن الكاملام هو عملية تبدأ صوتية وتنتهى بإتمام عملية إتصال مع متحدث من أبناء اللغة في موقف اجتماعي.

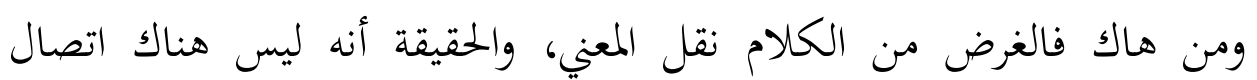
حقيقي دون معنى، ولا معنى حقيقي دون أن تتوافر فن الرسلة ناحية عقلية وناحية انفعالية اجتماعية، وهما ناحيتان تعطنيان للرسالة أهمية و معانيها.

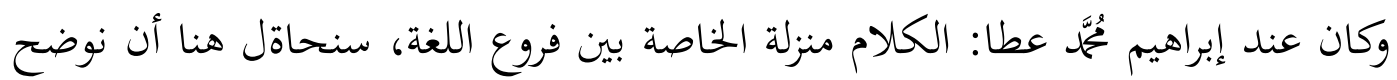
أهمية الكلام في الحياة نطاق محددة تكشف لنا جوانب من هذه الاهمية: ا. من المؤكد أن الكلام كوسيلة إفهام سبق الكتابة في الوجود، فالانسان قبل أن يكتب، ولذالك فإن الكلام خادم للكتابة. r. التدريب علي الكلام يعود الانسان الطلاقة في تعبير عن افكاره، والقدرة على المبادلة وموجهة الجماهير. r. الحياة المعاصرة بما فيما من حرية وثقافة، في حاجة ماسة ألى المناقسة، وإبداء الرأي،

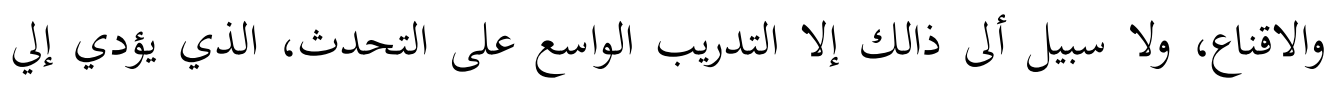
التعبير الواضح عما في نفسه. ع. الكلام- خصوصا في هذا العصر إلي يتعدد فيه وسائل النقل والمواصلات- ليس وسيلة لطمأنة الناس المتنقلين فقد، بل طمأنة أهليهم وذويهم، لأن في إنقطاع 
الاتصال بداية الخطر، فالمغترب والمسافر عندما يكلم أهله بالهاتف يطمئنهم، ويكلم رفاقة وأصدقائه فيطمئن عليهم.

ه. والكلام مؤشر صادق - ألى حدما- للحكم علي المتكلم، ومعرفة مستواه الثقافي،

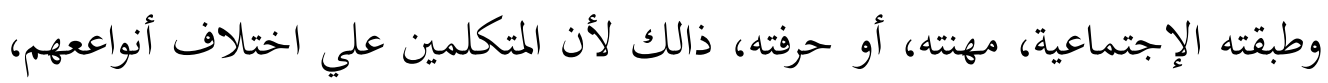

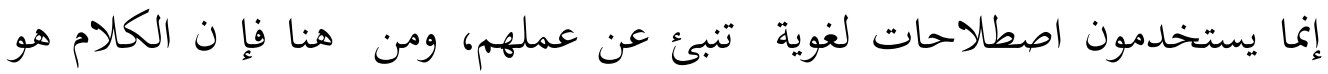
الإنسان، ولذالك قال بعض العلماء المنطق: إن الانسان حيوان ناطق.

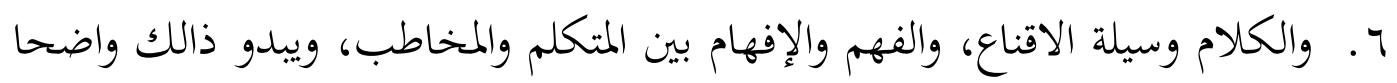

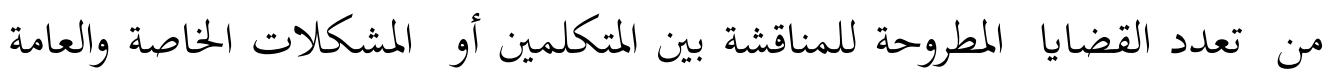
التى تكون محلا للخلاف. V. والكلام وسيلة لتنفيس الفرد عما يعانيه، لأن تعبير الفرد عن نفسه - ولو كان

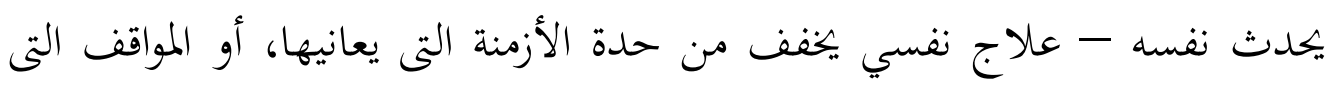
يعترض لما. 1. والكلام نشاط إنساني يقوم به الصغير والكبير، والمتكلم والجاهل، والذكر والأنتي، حيث يتيح للفرد فرصة أكثر فن التعامل مع الحياة، والتعبير عن مطالبة الضرورية. 9. والكلام وسيلة رئيسة في العملية التعليمية في مختلف مراحلها، لا يمكن أن يستغنى عنه معلم في أية مادة من المواد للشرح و التوضيح. ولا شك أن الكلام من أهم ألوان

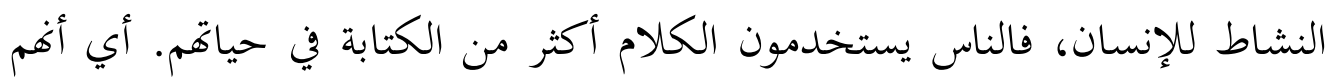

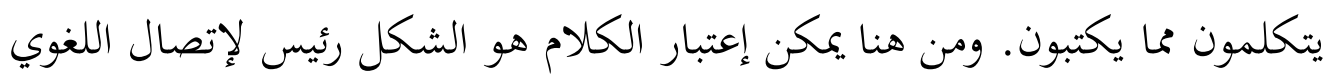
بالنسبة للإنسان. علي ذالك يعتبر الكلام أهم في الممارسة اللغوية و استخدامها.

\section{الإختبار المستخدمة فى تعليم مهارة الكلام}

أن واحد من الأهداف تدريس مهارة الكلام هو أن يصل بالدارس إلي مستوى معقولة من الطلاقة، أي القدرة علي التعبير بصورة مفهومة وسليمة و دونتلعثم أو تردد. 
وللوصول إلي هذا الهدف ينبغي النتقال بالدارسين من مرحلة المحاكاة المحضة إلي مرحلة يستطيعون فيها التعبير عن أفكارهم من خلال : أولا : التدريب علي عناصر اللغة و بصورة خاصة المفردات و التركيب. ثانيا: التدريب علي استعمال اللغة في مواقف التعبير عن المعاني الشخصية(بيرن، . ( $9: 19 \vee 7$

ومع أننا سنبدأ في السطور التالية بتناول اختبار الكلام عند الدارسين إلا أن هذا

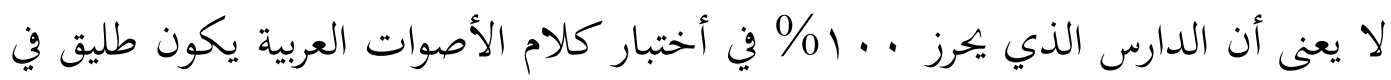

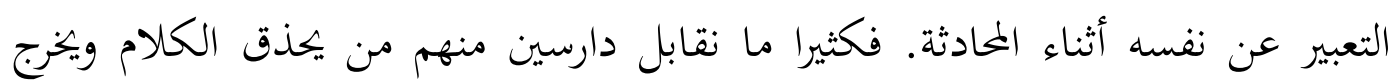

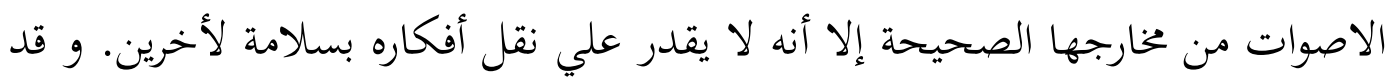

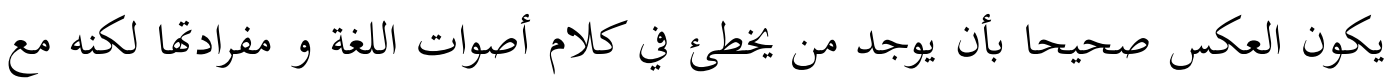
ذلك ينجح في التعبير عن نفسه في سهولة، و من هناك نقول إنه يجب علينا أن نفرق بين إكتساب التحكم في عناصر اللغة (أصواها و مفرداها و قواعد ها) و القدرة علي توصيل الأفكار و المعلومات من جانب آخر. وبتعبير آخر ينبغي أن نفرق بين أكتساب المهارة و استعمال المهارة. أنواع البنود هناك أنواع كثيرة من البنود يمكن من خلالها قياس قدرة الدارس علي الكلام بدءا بانقط السليم وانتهاء بالتعبير عن حاجاته. وسنتنالول هناك أهم هذه الأنواع والتي تبدأ هن هنئ من أسهل أنواع الأسئلة - التي تصلح للمبتدئين - إلي أكثر ها صعوبة وهي التي تصالح للصفوف المتقدمة. أولا : اختبار النطق يتناول اختبار النطق عادة أصوات اللغة العربية الرئيسية (الصوامت والصوائت) بالاضافة

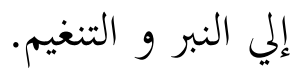


وفيها يختار المدرس كلمات أو جملا تحتوي علي الصوت أو الأصوات التي يؤد اختبار الدارس فيها، ثم يقوم بتسجيلها و يطلب من الدارس الاستماع ثم محاكاة

يسمع الدارس إلي بعض الجمل، ويطلب إليه إعادة ما يسمعه، وهذا نوع من

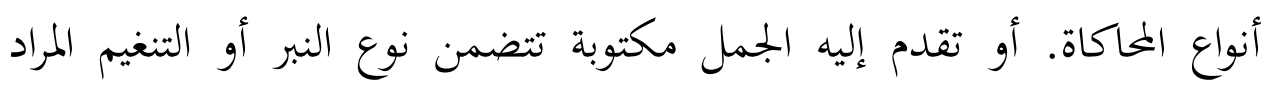
اختباره.

$$
\text { (ج). قراءة من الذاكرة }
$$

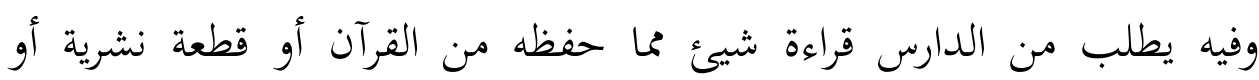
قصيدة أو حوار درسه، وأثناء ذالك يقوم المدرس باختبار نطقه في أصوات

$$
\text { (د). التكملة }
$$

ينبغي أن تكون البنود التي يختارها المدرس دقيقة حتي يجبر الدارس علي التكملة

$$
\text { (ه). هـا الصوت المراد اختباره. }
$$

هناك شبه كبير بين هذا النوع من البنود و بين اختبار المفردات، فكلهما يقومان علي استخدام الرسم ليأتي الدارس بالكلمة المناسبة. إلا أنه في أختبار النطق يعني بالصوت المراد اختبار داخل الكلمة، و في اختبار المفردات يعني بالكلمة كلها. و يفصل أن يقدم للدارسين مثير مكتوب.

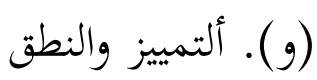


وهذا النوع يجمع بين بنود التمييز والإنتاج، نعطى للدارس بعض الكلمات وعليه أن يقوم بخطوتين، الأول: التعرف على الكلمة إلى بها الصوت المحالف، والثانية: نطق كلمة من عنده تشابه الواقع الموسيقي للكلمات الأخرى أو ما يطلب منه.

$$
\text { (ز) القراءة الجهرية }
$$

يمكن اختبار قدرة الدارس على النطق من خلال ملاحظة أثناء القراءة.

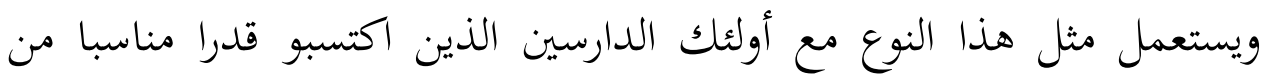
التمكن من قراءة الخطط العربي، ولا ينصح باستعماله مع المبتدئين.

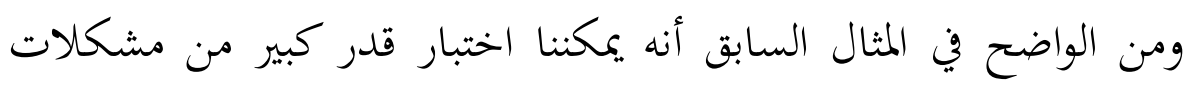
النبر و التنغيم إلى جانب الصوامت و الصوائت.

\section{ثانيا: اختبار التركيب شفهيا}

يقول هيتون أن تدريبات التركيب من الأساليب المفيدة و التي يمكن إدخالها ضمن بنود اختبارات الصف التحصيلية والشخصية، وهي تعد نوعا من أساليب المراجعة على التراكيب التي درست في المقرر. وتنقسم إلى قسمين رئيسين: آلية و طبيعية. وينبغى قبل أن يشرع الدارسون في الإجابة أن يعطى لهم مثالان أو ثلاثة لنمط الإجابة المطلوب، ونئ، تم بعد ذلك تقدم إليهم المثيرات شفهيا و يجيبون شفهيا أيضا. ( ) (أنواع البنود الآلية أ). التحويل ويمكن أن نتناول هنا كل أنواع التحويل، مثل التحويل من الإثبات ألى النفي.

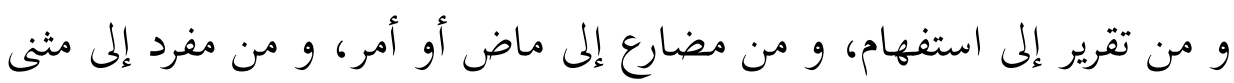
أو جمع... الخ أو العكس. ب). الربط أمثلة: اربط كل جملتتين. 


$$
\begin{aligned}
& \text { ج). (الاستبدال } \\
& \text { وهو من أكثر أنواع التدريبات الآلية شيوعا. } \\
& \text { r) (أنواع البنود الطبيعية } \\
& \text { أ). السؤال و الجواب } \\
& \text { ب). (ب) بارة و سؤال } \\
& \text { ج). عبارة و عبارة } \\
& \text { ثالثا: استعمال المثير البصري }
\end{aligned}
$$

يمكننا أن نستفيد من المعينات البصرية في اختبار مهارة الكلام كما استفدنا

$$
\begin{aligned}
& \text { منها في اختبار مهارة الاستماع من قبل، وذلك على النحو التالى: } \\
& \text { السرال عن المواعيد والمسافات والمقاييس والأوزان }
\end{aligned}
$$

يقوم المعلم بإعداد ججموعة من الرسومات والجدوال على شفافيات العارض الصلوي ثم يقوم بعرضها على الدارسين، فيسأل مثلا عن مواعد وصول مغادرة الطائرات أو الحافلات والقطاراتو والمسافة بين كل مطظتين ثم يسأل الدارسين كلا

$$
\begin{aligned}
& \text { منهم على حدة عن هذه المواعيد و المسافات. } \\
& \text { (ب). ق مراءة الأرقام }
\end{aligned}
$$

يقدم المدرس للدارسين قوائم أو طعام أو أسعار بعض السلع ويسأل عن سعر أكلة معينة أو سعر سلعة معينة. ويمكن أيضا أن يقدم عمليات حسابية بسيطة على بطاقات ومضية أو على جهاز العارض العلوي ويطلب من الدارسين قراءها أو استعمالها في جمل مفيدة.

$$
\text { (ج). وصف الشرائح }
$$

يقدم المثير هنا في شكل شرائح تتضمن معلومات عن الثاقفة والحضارة العربية

$$
\text { والإسلامية. }
$$


يقوم أحد الدارسين بأداء بعض الأفعال أو الحراكات، ثم يطلب المدرس من دارس آخر أن يلاحظ ما يفعله زميله و من ثم يقوم بوصف ما فعله (يفعله) زميله.

$$
\text { (ه). سرد قصة مصورة }
$$

تقدم للدارس صورة و يطلب منه دراستها، ومن ثم يقوم بحكاية. القصة التي تعبر عنها الصورة أو مجموعة الصور. وتعطى الدراجات على أساس الطلاقة العامة، واستخدام المفرادات وسلامة التعبير ودقة الوصف أو السرد.

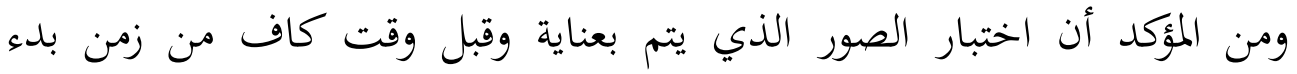
الاختبار "يساعد في عملية التحكم في المفردات الأساسية المطلوبة في الاختبار، ويمكن أن يحدد -إلى حد كما- نوع تركيب المواد اختباره. وإذا كانت الصورة أو

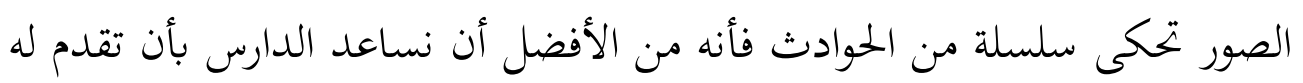

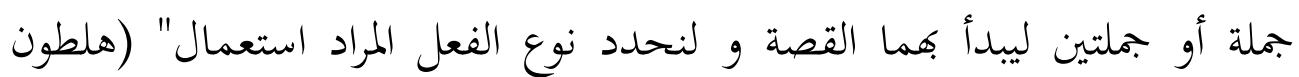

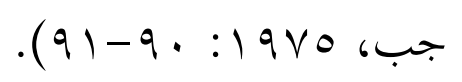

رابعا: المقابلة

المقابلة من أكثر اختبار مهارة الكلام شيوع. وفيها يستدعى الدارس لقياس أدائه الشفهي. ويمكن دور مدرس الصف أثناء المقابلة هو التفرغ لتقويم أداء الدرس.

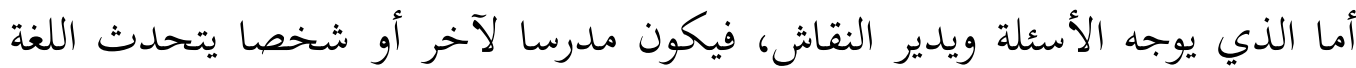

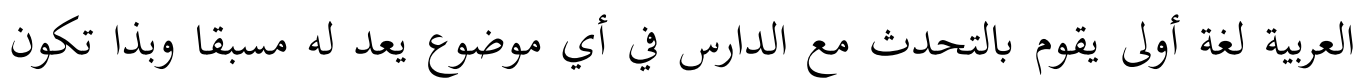
المقابلة واقعية الى حد ما. لمان.

$$
\text { (أ). مواضع المقابلة }
$$

من المفيد جدا أن تنبع مواضيع المقابلة من مواقف طبيعية للغة ودون سابق

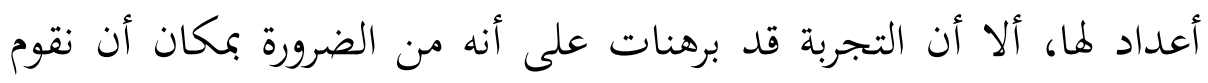
ـقببل بداء المقابلة_ بإعداد بعض المواضيح للرجوع إليها أذا ما دعت الحال خاصة إذا كان عدد الدارسين كبيرا. فكثير تستنفد معظم الآسؤلة والمواضيع 
Wahyudi Buska, Nurhasnah: Al-Ikhtibār al-Mustakhdamah Litarqiyati Mahārah al Kalāmi

التي قد اختزرها المدرس في ذاكرته أثناء حيثه مع الدفعة الأولى ثم يضطر الى تكرار المواضيع نفسها مع الدفعة الثانية التي يكون معظم أفرادها قد سأل

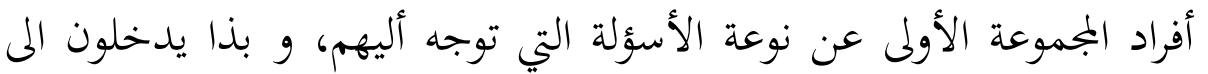

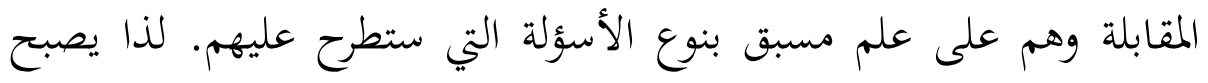
منالضرورة أن نعد قائمة - حتى وأن كانت برؤوس المواضيع - لتكون مرجعا

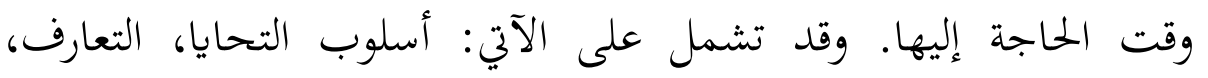

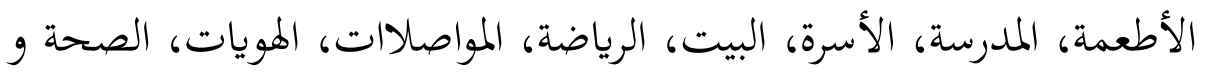

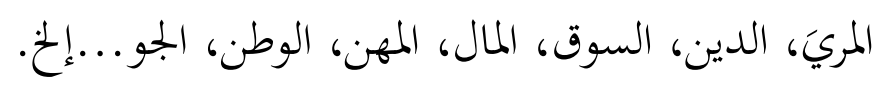

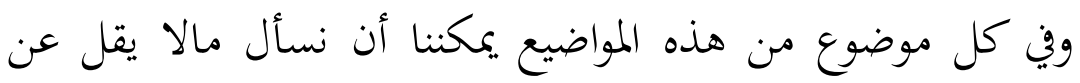

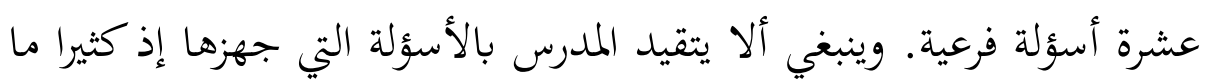
تفرض أسيلة معينة نفسها انطلاقا من المواقف أو السؤال السابق. (ب). (أساليب المقابلة

نسبة للأن المقابلة الشفهية من أكثر أنواع الاختبارات خصوعا للذاتية فمن الأفضل أن نعمل قدر لإمكان على التقليل من تدخل العوامل الذاتية، ويمكن أن يتم ذلك بأن يلتقي المدرسون الممتحنون والمصححون قبل إجراء الاختبار بوقت كاف للمناقشة وإقرار خطة عامة يتبعها الجميع مع كل الصفوف وعلى كل الدارسين، لأنه ما لم يتفق ويتبع كل المدرسون خطة موحدة لإجراء المقابلة - من حيث التوقيت ودرجة السرعة التي يتحدثون بها مع الدارسين وتطبيق معايير موحدة في القويم - فإن النتاؤج التي نغصل عليها لن تتسم باصدق والثابت الذين إذا فقدا في الاختبار فإن ذلك يعني أنه غير جيد ويعد تطبيقه حينئذ مضيعة للوقت. ومن الآفضل أن يجلس المصححون في جلسة موحدة ويستمعون الى المقابلات مسجلة في اختبارات سابقة تكون بمثابة نماذج. ثم يتناقشون في 
Wahyudi Buska, Nurhasnah: Al-Ikhtibār al-Mustakhdamah Litarqiyati Mahārah al Kalāmi

Fi Ta'līmi al-Lughah al-Arabiyyah

كيفية اإجراء ونوعية الأسئلة وتعليقات وطرق التقدير، وبذا يصلون إلى حد أذنى مشترك من التجانس حول كل ما يختص بمقابلة من حيث المحتوى

$$
\text { والإجراء والتصحيح. }
$$

(ج). خطة التصحيح

كما قلنا سابقا إن تصحيح أداء الدارس الشفهي أثناء المقابلة يخضع إلى حد كبير الى عوامل الذاتية، وربما تكون العوامل الذاتية أوضح فيها من تصحيح الأداء الكتابي. لذا ينبغى أن نعد مسبقا خطة تتضمن الجوانب التي نود تقيمها في الأداء الشفهي للدارس. و ينبغي أيضا تحديد الدرجات التي تعطى لكل جانب على كل حدة، مثل: الدقة في النطقي، النبر و التغنيم، النحو، والمفردات، الطلاقة، سهولة التعبير عن الفكرة، والفهم العام، وتلعثم، والتردد، طلب أعادة بعض الأسئلة. وكلما كانت الخطة دقيقة ومحكمة فأفها تقربنا من

$$
\text { الموضوعية في تقدير دراجات الدارسين. }
$$

ب - بلماتمة

إن عملية التعليم تتكون من ثلاثة عوامل مهمة لا يمكن التفريق بينها وآخر. وهذه العوامل الثلاثة هي الهدف التعليمي وتنفيذ عملية التعليم والتقييم.مالهدف التعليمي يتكون من المهارات التى يمكن وصوها بعد عملية التعليم.وأما العامل الثاني فهو تنفيذ عملية التعليم الذي يتكون من النشاطات للوصول إلى الهدف المقرر.وأما العامل الثالث فهو التقييم.وهذا الأخير يتعلق بالعاملين السابقين وبه سيعرف نجاح تنفيذ التعليم.وأما الأداة المهمة فن إنتاج عملية التعليم هي الاختباركوبه سيعرف الأحوال عنها كالتغذية الراجعة منها،وأداة الاختبار في تغيير المواد الدراسية وطريقتها وإستيراتيجية تنفيذها وأداة التقييم حتى تكون عملية التعليم فعالية و مجذبة. 


\section{المراجع}

\section{المراجع العربية}

أحمد فؤاد عليان. بوإ المهارات اللغوية ماهيتها و طرائق تدريسها.الرياض: دار المسلم عبد السيد.ب...r، تعليم اللغة اللغ العربية. الرسالة العلمية:فدع.

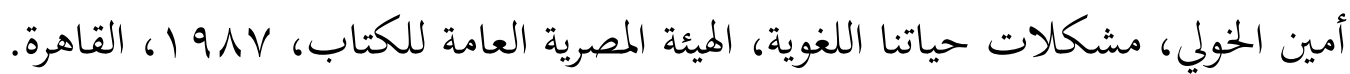

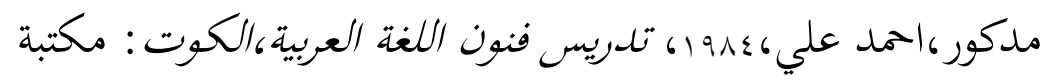

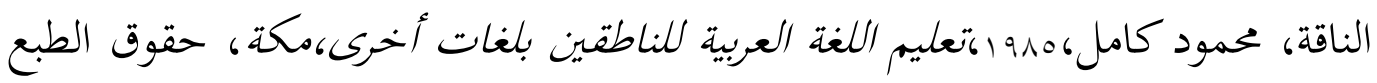
و إعادته مخفوظة لجامعة أم القرى.

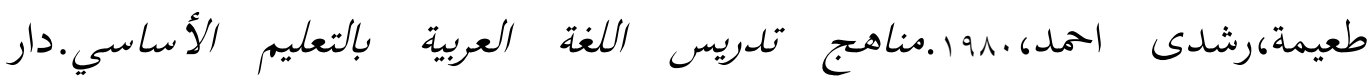
الفكرى:جامعة السلطان قابوس. حسن سليمان،979.1.تعليم الغة العربية دراسات تحليلية و مؤلغة تطبيقية،القاهرة:دار

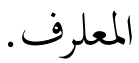

الغالي، ناصر عبد الله، وعبد الله عبد المجيد. بدون السنة.أسس أعداد الكتاب التعليمية لغير الناطقين بالعربي.الياض:دار الغالي.

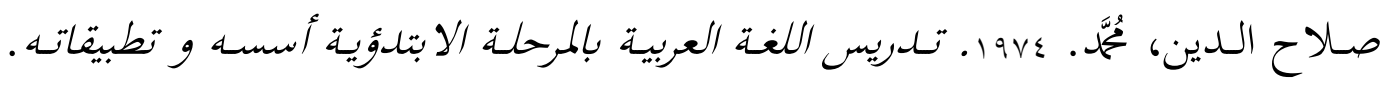
الكويت، للمطباعة النشر و التوزيع

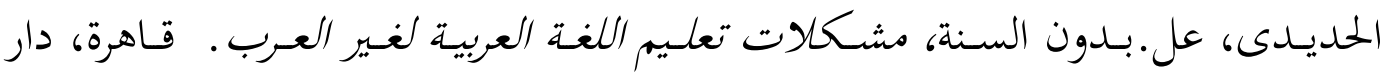

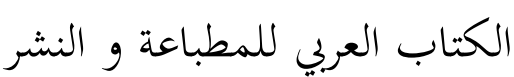

طعيمة، أحمد، رشدى. و919 . تعليم العربية الناطقين بها، مناهجه و اساليبه . الرباط: منشورة المنظمة الإسلامية لتربية و العلوم و الثقافة. -1991------- مناهج تلدريس اللغة العربيبة/لتعليم الأساسة. . قاهرة: دار الفكر. مختار، أحمد. بهو ا. علم الدلالة، مكتبة دار العربية لنشر و توزيع. 


$$
\begin{aligned}
& \text { الغـالي، ناصـر عبـد الله، و عبــ الله، عبـد الحميـد. بـدون السـنة. أسسس إعـلداد الكتـاب } \\
& \text { التعلمية لغير الناطقين بالعربي. الرياض: دار الغالى. } \\
& \text { منصور، عبد المجيد سيد أحمد. بهوا ـ علم اللغة النغسى. الرياض: جامعة الملك السعود. } \\
& \text { يوسف الصسميلي،1911م ، اللغة العببية وطرق تلدريسها تظرية وتطبيقا، بيروت: المكتبة } \\
& \text { العصرية. } \\
& \text { يُعطي د. حسن ظاظا في كتابه (كلام العرب، من قضايا اللغة العربية)، مكتبة الدراسات } \\
& \text { اللغوية، دار القلم دمشق، الدار الشامية بيروت، الطبعة الثانية }
\end{aligned}
$$

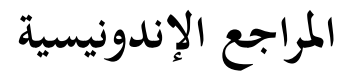

Bagawi, Ibnu Mas'ūd. 1997. Ma'àlimul Quran. Saudi Arabia: Maktabah Syāmilah Edisi Kedua.

Buska, W., Prihartini, Y., \& Hasnah, N. 2018. Analysis of Students' Arabic Proficiency for Vocabulary Mastery in State Islamic Junior High School in Muaro Jambi. INNOVATIO: Journal for Religious Innovation Studies, 18(1), 51-62.

Buska, W., Prihartini, Y., \& Hasnah, N. 2018. Dirâsah Tahlîliyyah Taqwîmiyyah 'An AlMufradât Fî̀ Kitâb Manân Al-Azîz. Arabiyat: Jurnal Pendidikan Bahasa Arab dan Kebahasaaraban, 5(2), 358-373.

Djajasudarma, T. Fatimah. 1993. Semantik: Pengantar ke Arah Ilmu Makna. Bandung: Eresco.

Fakih, M. 2010. Analisis Gender dan Transformasi Sosial. Yogyakarta : Pustaka Pelajar Hasyimi. Ahmad. 2006. Al-Qawaid al Asasiyah Li al-Lughah al-Arabiyah. Al Qahirah.

Ibnu Jarir, Muhammad. 2000. Jamī' Bayān F̄̄ Ta'wìlil Quran . Saudi Arabia: Maktabah Syāmilah Edisi Kedua.

Kas̄īr, Ibnu. 1999. Tafsīr Al-Quran. Saudi Arabia: Maktabah Syāmilah Edisi Kedua.

Mahali dan Suyuti. 2000. Tafsīr Jalālain. Saudi Arabia: Maktabah Syāmilah Edisi Kedua

Mahsun. 2011. Metode Penelitian Bahasa: Tahapan Strategi, Metode, dan Tekniknya. Jakarta: Rajawali Press.

Mughalasah. Muhammad Husaini. 1991. Al-Nahwu al-Syafi. Oman:Dar al-Basyir

Mustofa, Ibrahim, Ahmad Ziyad, Ahmad Abdul Qodir dan Muhammad Nujjar. 2000. AlMu’jamul Wasīt. Saudi Arabia: Maktabah Syāmilah Edisi Kedua

Nasution. Ahmad Sayuti Anshari, 2006. Bunyi Bahasa. Jakarta: Press .

Pateda, Mansoer. 1986. Semantik Leksikal. Flores: Nusa Indah.

Prihartini, Y., Buska, W. and Hasnah, N.H.N., 2019. The Implementation of Suggestopedia Method in Arabic Teaching for Qirā'ah. Innovatio: Journal for Religious Innovation Studies, 19(1), pp.27-42.

Prihartini, Yogia, and Wahyudi, Nuraini. "Peningkatan Maharah Al-Kitabah Melalui Penerapan Media Lauhah al-Juyub Pada Siswa MTsN Aceh Utara." Jurnal Literasiologi 1, no. 1 (2019): 59-78.

Prihartini, Y., \& Wahyudi, W. 2018. The Development of Integrated Learning Model To Improve Language Skills at Arabic Language. IJER (Indonesian Journal of Educational Research), 3(1), 9-14. 
Wahyudi Buska, Nurhasnah: Al-Ikhtibār al-Mustakhdamah Litarqiyati Mahārah al Kalāmi

Fi Ta'līmi al-Lughah al-Arabiyyah

Prihartini, Y., Wahyudi, W., Aliasar, A., Mukhaiyar, M., \& Ungsi, A. O. M. 2018. The Development of Arabic Learning Model by Using Multimedia of Computer at UIN STS Jambi. Al-Ta lim Journal, 25(2), 135-143.

Prihartini, Y., Wahyudi, W., Nuraini, N., \& DS, M. R. 2018. Penerapan Konsep Matematika Dalam Pembelajaran Bahasa Arab Pada FTK Di UIN STS Jambi. Tarbawi: Jurnal Ilmu Pendidikan, 14(2), 15-28.

Prihartini, Y., Buska, W., \& Hasnah, N. 2019. Analysis of Test Item on The Final Test Semester Exam on Arabic Subjects. Arabiyat: Jurnal Pendidikan Bahasa Arab dan Kebahasaaraban, 6(1), 71-92.

Prihartini, Y., \& Buska, W. 2019. نحو استر/تيجية جديدة في تدريس مهارة الاستهاع وأساليب تدربيسها في . تعليم اللغة العربية. Al-Uslub: Journal of Arabic Linguistic and Literature, 3(1), 50-66.

Qoyyim, Ibnu. 2000. Tafsir Ibnu Qoyyim: Tafsir AyatAyat Pilihan. Terjemahan Suhardi. Jakarta: Darul Falah.

Qurtubi. 2000. Tafsir Qurtubi. Saudi Arabia: Maktabah Syāmilah Edisi Kedua

Ratna, N. K. (2010). Teori, Metode, dan Teknik Penelitian Sastra dari Strukturalisme hingga Postrukturalisme Perspektif Wacana Naratif. Yogyakarta: Pustaka Pelajar

Ridha, D. S. M., Buska, W., \& Prihartini, Y. 2020. The Development of Character Education Curriculum Model for Islamic Elementary Schools In Muaro Jambi. In Journal of Physics Conference Series (Vol. 1471, No. 1, p. 012030).

Satoto, S. 2014. Metode Penelitian Sastra. Yogyakarta: Yuma Pustaka

Setyawati. (2013). Analisis Kesalahan Berbahasa Indonesia. Bandung: Yuma Pustaka

Shihab, M. Quraish. 1994. Membumikan Al-Quran: Fungsi Dan Peran Wahyu dalam Masyarakat. Bandung: Mizan Media Utama.

Sugiyono. 2012. Memahami Penelitian Kualitatif. Bandung: Alfabeta

Sugihastuti, S. (2005). Kritik Sastra Feminis Teori dan Aplikasinya. Yogyakarta: Pustaka Pelajar

Shihab, M. Quraish. 2000. Wawasan Al-Quran. Bandung: Mizan Media Utama.

Sumardi Suryabrata ‘Metodologi Penelitian 'Cetakan Ke-33 ( Jakarta: PT. Grapindo Persada) 2012

Tontowi, Muhammad. 2000. Tafsīr Wasīt. Saudi Arabia: Maktabah Syāmilah Edisi Kedua.

Verhaar, J.W.M. 1992. Pengantar Linguistik. Yogyakarta: Gadjah Mada University Press.

Wahyudi, W. 2018. Tingkat Kelayakan Tes Uas Bahasa Arab Pada Fakultas Ilmu Tarbiyah Dan Keguruan Di Uin Sulthan Thaha Saifuddin Jambi Tahun Ajaran 2016-2017. Jurnal Al-Ashlah, 1(2).

Wahyudi, W., \& Prihartini, Y. 2019. Development of Arabic Learning Material Based on Eclectic Method. In 3rd Asian Education Symposium (AES 2018). Atlantis Press.

Wahyudi, W. 2016. Pemberdayaan Mahasiswa Jurusan Syariah Seiring Dengan Perkembangan Iptek Dalam Menyongsong Era Reformasi. Islamika: Jurnal IlmuIlmu Keislaman, 14(2).

Wahyudi, W., \& DS, M. R.2017. Urgensi Mempelajari Psikolinguistik Terhadap Pembelajaran Bahasa. Islamika: Jurnal Ilmu-Ilmu Keislaman, 17(1), 113-140.

Zuhaili, Wahbah. 2001. Tafsīr Al-Wasīt.Damaskus: Darul Fikr. 